\title{
ROLE AND PLACE OF ULTRASONOGRAPHY IN DIAGNOSTICS OF ADHESIVE INTESTINAL OBSTRUCTION
}

DOI: 10.36740/WLek202001115

\author{
Vadim B. Borisenko, Artem N. Kovalev, Tatyana A. Denysiuk \\ KHARKIV MEDICAL ACADEMY OF POST-GRADUATE EDUCATION, KHARKIV, UKRAINE
}

\begin{abstract}
The aim: To study the possibilities of ultrasound in adhesive ileus obstruction diagnosis and indications for surgical treatment determination.

Materials and methods: The results of diagnosis and treatment of 60 patients with acute adhesive intestinal obstruction with comparative use of $\mathrm{X}$-ray and ultrasound methods were analyzed.

Results: The use of a standard X-ray examination of the abdominal organs upon admission to the hospital allowed the diagnosis of acute adhesions of small bowel obstruction in only 32 (53.3\%) patients. Transabdominal ultrasonography allowed the establishment of adhesive ileus during hospitalization in 53 (88.3\%) patients and also in 7 (11.7\%) during a dynamic examination 2-3 hours after admission. Due to the lack of positive effect from the conducted conservative therapy relying on the data of ultrasound studies, 33 (55\%) patients were operated on. During X-ray examination, only 10 (30.3\%) of these patients demonstrated negative X-ray dynamics, and with an ultrasound study, deterioration of echo pictures was observed in all $33(100 \%)$ patients.

Conclusions: Compared with the X-ray method, transabdominal ultrasonography is established to be safe, affordable, simpler, non-invasive and highly informative method for the study of acute adhesions of the small intestinal obstruction. The method allows the assessment of the ongoing conservative therapy dynamics and determination for surgical treatment indications.
\end{abstract}

KEY WORDS: acute adhesive small-intestine obstruction, diagnostics, X-ray, ultrasonography

Wiad Lek. 2020;73(1):83-86

\section{INTRODUCTION}

Acute adhesive small-intestine obstruction (AASIO) still remains complicated and not fully resolved surgical problem. Its relevance primarily depends on the growing number of various planned and urgent abdominal operations complicated by AASIO progress in up to $20 \%$ of cases as well as high percentage of post-operative complications (8-31.4\%) and mortality up to $25 \%[1,2,3,4,5]$.

High AASIO recurrence rate up to $30-69 \%$ with further open adhesiolysis performance with post-operative mortality at the level of $55 \%$ adds relevance to the problem. $[6,7,8,9]$.

AASIO in accordance with its pathogenic origin differs from classical mechanical ileus and is inherently a mixed form of small-intestine obstruction. Its share in the general structure of acquired acute intestinal obstruction (AIO) according to summary data of some authors comes near $50 \%[1,3,10]$.

AASIO diagnostic algorithm is not standardized, so high percentage of diagnostic errors (16-34\%) remains even in conditions of hospital for in-patients, X-ray method of ileus diagnostics still remains prevalent $[8,9,11]$.

X-ray computer tomography (CT) able to diagnose AASIO with high level of accuracy and carry out differential diagnostics with other types of intestinal obstruction has recently been widely publicized. Though CT is more often used as additional method of the study with ambiguous interpretation of the data of standard instrumental diag- nostics and not always can be used because of its costliness and limited availability $[11,12]$.

Unfortunately such simple, safe and highly informative and affordable method of AASIO diagnostics as ultrasound study (USS) still finds no wide practical application [1], its application will allow the improvement of diagnostics results and adhesive ileus treatment.

\section{THE AIM}

The aim of the study is to investigate the abilities of USS method in adhesive ileus diagnostics and surgical treatment determination.

\section{MATERIALS AND METHODS}

The work is based on the analysis of diagnostics results and surgical treatment of 60 patients with AASIO being treated in the surgical department of Kharkov CCGH №25 and PHF "Valkovskaya CRH" in 2015-2018.

Men were 27 (45\%), women - 32 (55\%). The age of the patients varied from 18 to 78 years old, average age comprised $62 \pm 12$. Post-operative ventral hernia was found in 7 (11.7\%) patients from them, umbilical hernia - in 2 (3.3 $\%)$, history of abdominal trauma - in 1 (1.7\%).

Besides standard physical studies diagnostic algorithm included history taking with data refinement as for pres- 
ence and character of previously conducted operations, inflammatory abdominal diseases and abdominal trauma.

Instrumental stage of the investigation included abdominal organs ( $\mathrm{AO}) \mathrm{X}$-ray study upon admission and in treatment dynamics (from 2 to 6 hours) after giving contrast. In the diagnostics of AIO intestinal pneumatosis presence, Kloiber bowls and small-intestine "arches", small intestine (SI) "cross striation" symptom were taken into account.

Regardless X-ray study AO USS was done upon admission and in conservative treatment dynamics in "real time" with the use of $3.5-5 \mathrm{MHz}$ convex sensor. USS was done without initial preparation of the patients in lying and standing position. The intestine was studied poly-positionally and poly-projectionally with the search of optimal "ultrasound window". Revealing of extended and angulated SI loops, intraluminal deposition of liquid and flatus, pendulum chyme movement presence, restriction of mobility of peritoneal sheet and CT at forced "belly breathing" were considered echo-sonographic symptoms of AASIO. The thickness of intestine wall, the height of Kerkring folds and the distance between them were also measured and compared in dynamics, peristalsis depth and frequency of SI loops were studied. Free abdominal liquid presence, stomach contents congestion and pathologic foci (tumors, foreign bodies, etc.) were determined.

The results of the study were statistically processed with the use of standard Microsoft Excel 2010 program package.

\section{RESULTS AND DISCUSSION}

At hospitalization the diagnosis of AASIO was clear in 32 (53.3\%) patients, in 22 (36.7\%) cases the signs were moderately pronounced and in $6(10 \%)$ - poorly expressed or absent.

According to the history data in 55 (91.7\%) patients $\mathrm{AO}$ and retroperitoneal operations had been previously performed. In 12 (20\%) of them cavity operations were done twice and more, $6(10 \%)$ patients were operated on AASIO earlier.

It was stated that in $5(8.3 \%)$ patients $\mathrm{AO}$ operations were not earlier performed. In $2(4.2 \%)$ cases incorrigible umbilical hernia was diagnosed. In 2 (3.3\%) more patients a history abdominal trauma was found. 1 (1.7\%) patient earlier received conservative treatment for appendicular infiltrate without further appendectomy.

At X-ray study upon admission to the hospital AIO was confirmed only in $32(53.3 \%)$ patients with pronounced and moderate clinics. Multiple Kloiber bowls and small intestine "arches" were found in them, in $8(13.3 \%)$ cases cross striation of SI was found. In remaining 28 (46.7\%) cases patients manifested no pathology or only local SI pneumatosis were found (fig.1).

The conducted transabdominal USS to the patients upon admission to the hospital allowed determination of ASSIO in $53(88.3 \%)$ patients. In $7(11.7 \%)$ more cases the ultrasound picture of AIO was found at dynamic USS in 2-3 hours after initial examination. Echographically in all $60(100 \%)$ patients the phenomenon of "fluid sequestra- tion" into the intestine lumen and hyperpneumatosis of its leading gut were found (fig.2). The diameter of extended SI loops, filled with liquid varied from 2.6 to $4.4 \mathrm{~cm}$ and comprised in average $3.2 \mathrm{~cm} \pm 0.3 \mathrm{~cm}$. Back-and-force SI chyme motions were found in $58(96.7 \%)$ patients, and its wall thickening comprised $0.4 \mathrm{~cm} \pm 0.01 \mathrm{~cm}$. Intraluminal content of SI allowed the visualization of its mucosal folds (fig.3). Kerkring folds of the greatest size were found in its primary tracts, their height was $1.1 \mathrm{~cm} \pm 0.02 \mathrm{~cm}$, and the distance between them was $1.1 \mathrm{~cm} \pm 0.01 \mathrm{~cm}$.

The level of obstruction was judged about the data of SI loops localization in abdomen as well as clarity of mucosal wrinkles which height and number decreased sufficiently in its distant region.

The conducted USS allowed the determination of free from adhesive process abdominal regions as well as various degree of SI loops fixation clarity by adhesions between themselves and to parietal peritoneum of the anterior abdominal wall. Mobility of SI loops regarding anterior abdominal wall at forced belly breathing of the patient was decreased and comprised $1.4 \pm 0.6 \mathrm{~cm}$ (in remote zones it was $3,7 \pm 0,7 \mathrm{~cm})$.

In $8(13.3 \%)$ patients at primary USS and in $10(16.6 \%)$ more at repeated study interloop (fig 3 ) and free liquid were found in various abdominal areas in the amount from 200 to $1000 \mathrm{ml}$, which in no case was determined on X-ray. The given ultrasound sign is the objective criteria of the negative dynamics of the disease course and an indication to urgent surgery.

In $27(45 \%)$ patients after conducted conservative treatment the improvement of clinic-instrumental picture was marked. On X-ray the number of Kloiber bowls and small intestine "arches" disappeared or decreased in these patients, intestine pneumatosis regressed, in 6-12 hours the contrast was found in colon.

In its turn with echosonography in the same patients positive ultrasound dynamics was marked in 2-3 hours after conservative therapy. Reducing of the width of SI lumen, Kerkring folds height were found, chyme motions became progressive which proved about SI passability.

In $33(55 \%)$ patients positive effect from conducted conservative therapy was not marked and they were later operated on. On X-ray only in 10 (30.3\%) from these patients negative X-ray dynamics was marked with Kloiber bowls number and size growth, appearance of small intestine "arches" and SI cross striation. Absence of contrast in colon and presence of contrast depot in SI (fig 4) predetermined indications to operative treatment of these patients.

On USS worsening of echo picture was observed in all $33(100 \%)$ patients. SI diameter increased in $3.4 \mathrm{~cm} \pm 0.1$ $\mathrm{cm}$, chyme stratification was found in it. Kerkring folds height and distance between them increased up to $1.2 \mathrm{~cm}$ $\pm 0.1 \mathrm{~cm}$ and $1.3 \mathrm{~cm} \pm 0.1 \mathrm{~cm}$, consequently. Slowing down of back-and-forth motions of chyme was marked which proved about SI peristalsis oppression.

On X-ray dynamic study of contrast passage vomiting and stomach drains presence presented complications in objective assessment of its progress after oral intake. The 


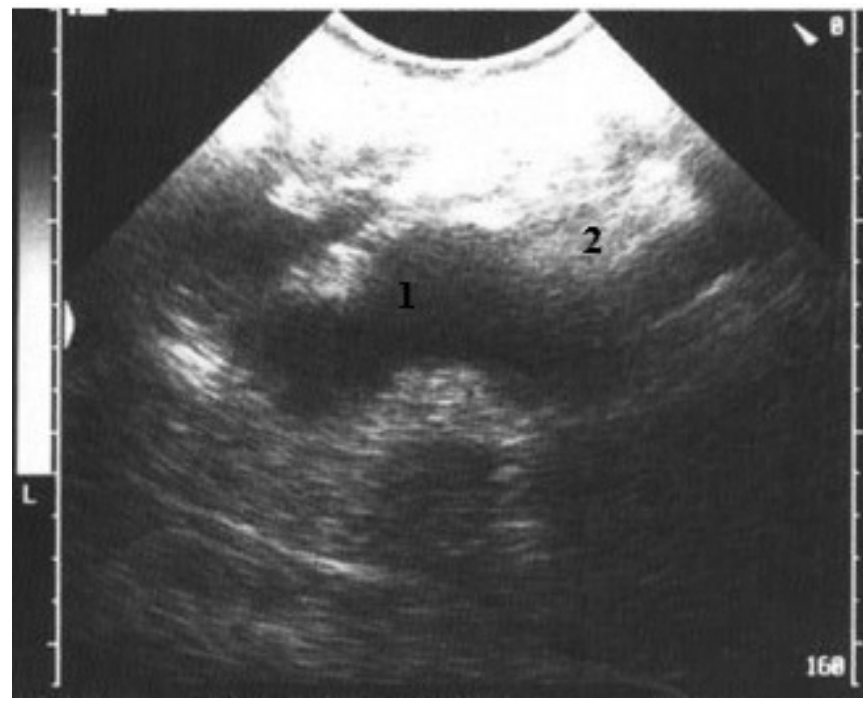

Fig. 1. $X$-ray of the patient $A$, after 3 hours from the onset of the disease. Only small intestine pneumatosis is determined (1)

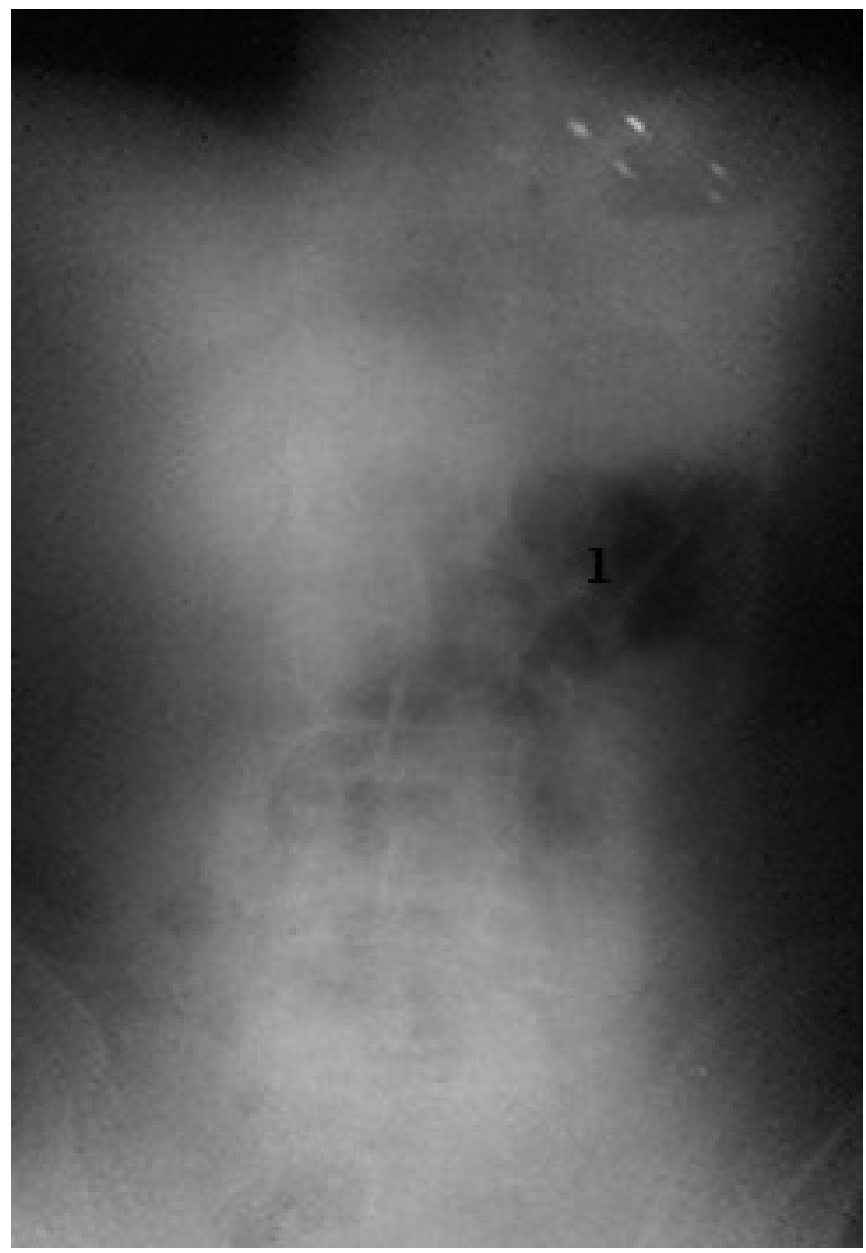

Fig. 2. Echogram of the patient A. High AASIO, 3 hours from the onset of the disease. SI lumen dilation with fluid (1) and flatus (2) deposition is determined

lack of methodology is later in comparison with USS assessment of the results (in 6 hours and more) and necessity to perform multiple X-rays.

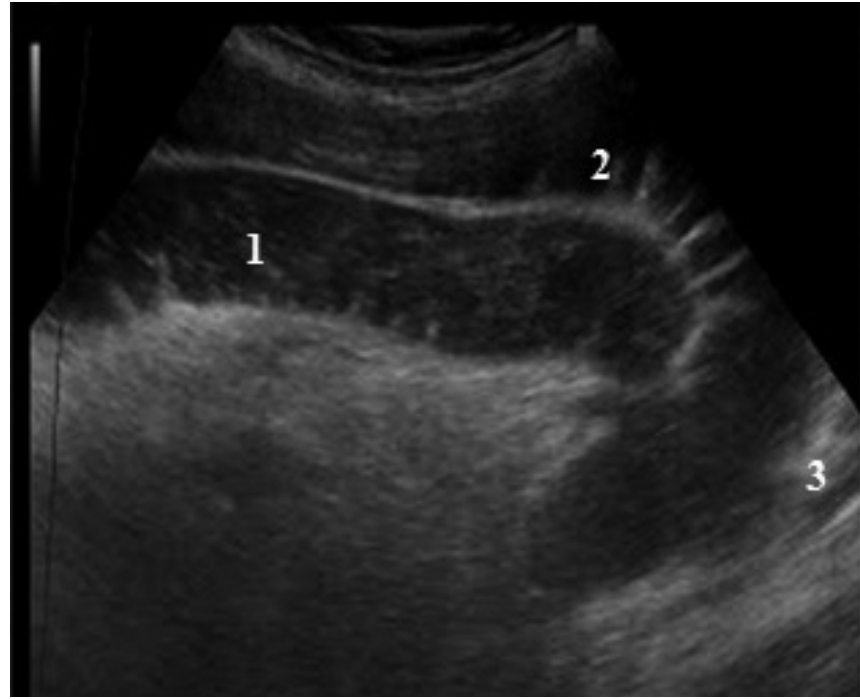

Fig. 3. Patient B. Echogram of the left iliac region. ASSIO, 6 hours from the onset of the disease: ileum lumen dilation with fluid deposition (1), lengthening and thickening of Kerkring folds (2), abdominal free liquid (3)

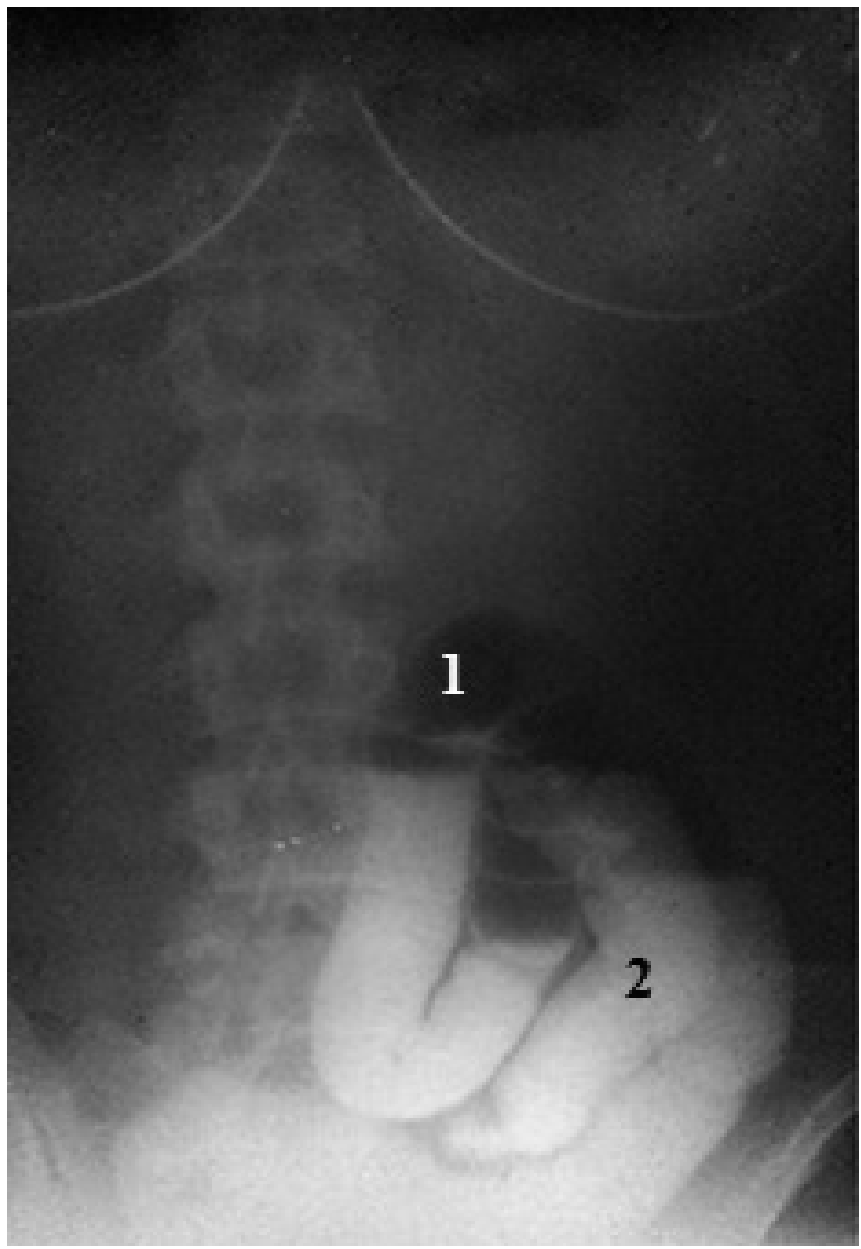

Fig. 4. X-ray of the patient B. After 3 hours after contrast giving. Flatus (1) and contrast depot in ileum (2) are determined

$33(55 \%)$ patients in all were operated on. 8 (13.3\%) patients were operated urgently after preoperative preparation and $25(41.7 \%)$ more were operated on as the result 
of inefficiency of conservative therapy. Various options of adhesiolysis were conducted to the patients, SI resection was done in $3(9.1 \%)$ cases. Besides adhesiolysis allodherinoplasty was conducted in $2(6.1 \%)$ patients, cholecystectomy about cholelithiasis - in 3(9.1\%) cases and appendectomy - in $1(3.0 \%)$ patient in combination.

Thus basing on a number of works of domestic and foreign authors $[2,3,4,7,8,10]$ so far the X-ray ASSIO diagnostics remains the primary method which is inherently more expensive, difficult to perform in serious patients and as a rule less informative upon admission of the patient to the hospital than USS. In its turn CT is highly informative, but costly method of ASSIO diagnostics. From our point of view CT should not be used during ASSIO routine diagnostics, but only with ambiguous interpretation of traditional diagnostics methods.

Our study allows the approach to adhesive ileus diagnostics from new positions, and the worked out program with USS priority use allows the statement of detailed diagnosis in short terms, the definition of the efficiency of the conservative treatment by several objective criteria. More than that, the value of the program is in getting pathognomonic preoperative data allowing the definition of clear indications to urgent surgical treatment. Correct interpretation of the received echographic data allows the definition of localization, extent, prevalence of the adhesive process and particularly involvement of parietal peritoneum of the anterior abdominal wall into it, which is important when undertaking atraumatic "rational" operative access to abdominal organs. The received results testify in favor of more wide and routine use of USS method in ASSIO diagnostics due to its accessibility, safety and high informativeness.

\section{CONCLUTIONS}

1. Comparative study of X-ray and USS methods efficiency allowed to state, that ultrasonography sensitivity during ASSIO initial diagnostics approaches $100 \%$, while X-ray comprises $53.3 \%$.

2. Transabdominal ultrasonography is an invasive, accessible and highly informative method of ASSIO diagnostics, having a number of advantages in comparison with X-ray method, being safer, more simple and possible to be used even with seriously ill patients.

3. Wide implementation of ultrasonography in the AIO diagnostics will allow the improvement the examination results and, respectively, treatment of this category of patients.

\section{REFERENCES}

1. Borisenko VB, BardjukAJ, Kovalov AM. Kompleksnaja diagnostika ostroj neprohodimosti kishechnika. Klinichna hirurgija. 2016; 10: 17-20. (In Ukrainian)

2. Dejkalo IM. Porivnjannja rezul'tativ operacijnogo likuvannja spajkovoï tonkokishkovoï neprohidnosti z vikoristannjam vidkritih ta laparoskopichnih tehnologij. Shpital'na hirurgija. 2016; 2: 85-88. (In Ukrainian)
3. Radzihovskij AP, Beljaeva OA, Kolesnikov EB i dr. Neprohodimost' kishechnika: rukovodstvo dlja vrachej. 2012:504.

4. Scott Fl, Osterman MT, Mahmoud NN, Lewis Secular JD. Trends in Small Bowel Obstruction and Adhesiolysis in the United States, 1988-2007. Am J Surg. 2012; 204: 315-320.

5. Xiao-Li Chen, Feng Ji, Qi Lin et al. A prospective randomized trial of transnasal ileus tube vs nasogastric tube for adhesive small bowel obstruction. World J Gastroenterology. 2012; 18: 1968-1974.

6. Behman R., Nathens AB, Byrne JP et al. Laparoscopic surgery for adhesive small bowel obstruction is associated with a higher risk of bowel injury: a population-based analysis of 8584 patients. Ann Surg. 2017; 266: 489- 498.

7. Byrne J, Saleh F, Ambrosini L. et al. Laparoscopic versus open surgical management of adhesive small bowel obstruction: a comparison of outcomes. Surgical endoscopy. 2015; 29: 2525-2532.

8. Catena F, Di Saverio S, Coccolini F. et.al. Adhesive small bowel adhesions obstruction: Evolutions in diagnosis, management and prevention. World J. Gastrointest. Surg. 2016; 8: 222 - 231.

9. InukaiK, Kitagami H, UeharaS. et al. A rare case of secondary small bowel volvulus laparoscopically repositioned: literature review and classification. Surgical Case Reports. 2018; 4: 65.

10. Liaqat N. Transection of gut loop due to post-operative adhesions. APSP J Case Rep. 2013; 4: 11.

11. Millet I, Ruyer A, Alili C. et al. Adhesive small-bowel obstruction: value of $\mathrm{CT}$ in identifying findings associated with the effectiveness of nonsurgical treatment. Radiology. 2014; 273: 425 - 432.

12. Kozlova AJ, Mumladze RB, Olimpiev MJ. Rol' rentgenovskoj komp'juternoj tomografii. Anally hirurgii. 2013; 4: 5-11. (In Russian).

This work is a fragment of SRW "Complex prophylactics of purulent-inflammatory complications in patients with abdominal organs emergency diseases". Number of state registration №0111U003580.

ORCID and contributionship:

Vadim B. Borisenko - 0000-0003-4723-2303 A,B,D,E,F

Artem N. Kovalev - 0000-0001-8042-8151 B,C

Tatyana A. Denysiuk - 0000-0002-1743-8354 B,C

\section{Conflict of interest:}

The Authors declare no conflict of interest

\section{CORRESPONDING AUTHOR \\ Vadim B. Borisenko}

Kharkiv Medical Academy of Postgraduate Education

222/69, Klochkivska Str., 61045, Kharkiv, Ukraine

tel: +380974865935

e-mail:vabodoc@ukr.net

Received: 19.04 .2019

Accepted: 07.11.2019

A - Work concept and design, B - Data collection and analysis, C - Responsibility for statistical analysis,

D-Writing the article, $\mathbf{E}$-Critical review, $\mathbf{F}-$ Final approval of the article 